This is the author accepted manuscript of:

A. R. Estabragh; M. Kholoosi; F. Ghaziani; and A. A. Javadi, Mechanical and Leaching Behavior of a Stabilized and Solidified Anthracene-Contaminated Soil". Journal of Environmental Engineering, Volume 144 Issue 2, article 04017098 (February 2018)

This material may be downloaded for personal use only. Any other use requires prior permission of the American Society of Civil Engineers. This material may be found at https://doi.org/10.1061/(ASCE)EE.1943-7870.0001311 


\section{A. R. Estabragh}

Associate Professor. Faculty of Soil and Water Engineering, University of Tehran, PO BOX 4411 Karaj 31587-77871, Iran

Tel: +98 2632241119

Fax: +982632226181

Email: raeesi@ut.ac.ir

\section{Kholoosi}

Postgraduate Student, Faculty of Soil and Water Engineering, University of Tehran, PO BOX 4411 Karaj 31587-77871, Iran

Tel: +98 2632241119

Fax: +98 2632226181

Email: mm.kholoosi@ut.ac.ir

\section{F.Ghaziani}

Assistant Professor, Faculty of Agricultural, University of Tehran, PO BOX 4411 Karaj 31587-77871, Iran

Tel: +98 2632248082

Fax: +98 2632246752

Email: FGhaziani@ut.ac.ir

\section{A. A. Javadi}

Professor, Computational Geomechanics Group, College of Engineering, Mathematics and Physical Sciences, University of Exeter, Devon, EX4 4QF, UK Tel: +44 1392723640

Fax: +44 1392217965

Email: a.a.javadi@exeter.ac.uk 


\title{
Mechanical and leaching behavior of a stabilized and solidified anthracene-contaminated soil
}

\begin{abstract}
This paper presents an investigation into remediation of an anthracene-contaminated clay soil through experimental tests. Samples were prepared of uncontaminated and contaminated soil-cement with 20 and $30 \%$ cement. Unconfined compression tests (UCT) were conducted on the natural soil and soil contaminated with anthracene. In addition, similar tests were carried out on uncontaminated and contaminated soil-cement at different curing times. Leaching tests were also conducted on contaminated soil and contaminated soil-cement with 20 and $30 \%$ cement at different curing times by using HPLC (High Performance Liquid Chromatography) apparatus. The results show that adding cement to contaminated soil increases the strength of the soil and the amount of increase in strength is a function of percent of cement and curing time. The results of the leaching tests on the contaminated soil show a major reduction in concentration of anthracene. The results also indicate that adding cement to the anthracene-contaminated soil causes a reduction in the concentration of anthracene after leaching tests and the amount of reduction is increased with increasing the curing time for a given cement content (20 or $30 \%)$. Increasing the percent of cement is an important factor in the reduction of concentration of anthracene.
\end{abstract}

Keywords: Anthracene, Contaminated soil, Soil-cement, Leaching test, Concentration, Curing time 


\section{Introduction}

A contaminant can be generally described as a chemical element, ion or compound that has the ability to pose an immediate or long-term threat to human health or the environment, mainly as a result of its toxic properties. Contaminants can be divided into two groups, organic and inorganic contaminants. Many organic compounds originate from crude oil. The components of crude oil must be partially separated by distillation and if necessary modified prior to being useful. Many types of organic contaminants can result from this process and can be found polluting the environment due to leakage from underground or aboveground storage tanks and accidental spills.

When soils are contaminated with chemical compounds they are absorbed or trapped within the soil and soil pore. These actions are influenced by factors such as particle size, bonding characteristics between particles and ion exchange capacity of soil particles. The arrangement of clay particles in a mass of soil is termed fabric. The fabric has significant effect on the behavior of soils. It is generally accepted that the clay soils have micro and macro fabrics. The role of micro fabric in physical and chemical interaction of clay soil with contaminating substance is more than that of the macro fabric. Micro fabrics exist between platelets or between platelets and independent unit layers of clay soil. Lagaly et al. (2006) stated that the organic molecules can intercalate into the interlayer space of clay minerals and the intercalated guest molecules can be displaced by other suitable molecules. The interlayer cations can be exchanged by various types of organic cations. With the advent of scanning electron microscopy (SEM) technique significant information about the fabric of soils became available (Collins and McGown, 1974). 
Researchers such as Tremblay et al. (2002), Botta et al. (2004), Cai et al. (2006) and Estabragh et al. (2016) used SEM technique for description of soil under different conditions (contaminated, mixed with cement, etc.)

The penetration of contaminant components from soil into groundwater can cause serious problems. There are several techniques for treatment of contaminated soils including physical, biological and chemical techniques. Stabilization and solidification $(\mathrm{S}-\mathrm{S})$ is one of the chemical techniques that is used for treating contaminants (Bishop, 1990). Stabilization refers to the fixation of a contaminant to the chemical structure of a soil material whilst solidification refers to the cementation of the soil material due to the addition of a solidification reagent such as lime, or cement. This process is responsible for lowering the soil permeability which results in reduction of contaminants and enhancement of the soil strength (Chen, 2009). Therefore, this method prevents from contaminant transport to groundwater, reduces the mobility of the contaminant in soil, or changes the contaminant into a non-toxic form. Wiles (1987) and Leonard and Stegemann (2010) indicated that S-S is one of the most cost effective methods for treating contaminated soils.

Portland cement is commonly utilized as binder in S-S remediation (Liu et al., 2012 and Paria and Yuetl, 2006). By using cement, heavy metals are converted to stable forms and are entrapped in the solid cementation matrix of the stabilized contaminant soil (Paria and Yuetl, 2006). Strength, permeability and leaching properties of S-S treated soils have been extensively studied by Yilmaz et al. (2003), Antemir et al. (2010), Kogbara and AlTabbaa (2011) and Du et al. (2012) among others. Conner (1993) indicated that S-S with addition of cement-based binders is an established treatment technology for soils 
contaminated with inorganic compounds whereas relatively limited experience exists for its application to organic compounds, in particular petroleum hydrocarbons. Organic compounds retard the cement setting process and affect the cement hydration by retarding reaction via formation of a protective film around the cement grain, hindering the formation of calcium hydroxide (Chandra and Flodin 1987; Edmeades and Hewlett 1998; Montgomery et al. 1991a; Sora et al. 2002). Gussoni et al. (2004) conducted experimental tests by proton nuclear magnetic resonance (NMR) imaging to investigate the cementation and hardening of cement in the absence and presence of organic compounds in soil. They found that a considerable delay occurs in the cement hardening when organic matters are present in the soil. Recently there have been some studies on the use of cement for S-S remediation and stabilization of soils contaminated with organic components (Donnelly and Webster; 1996, Bettahar et al.; 1999 and Yilmaz et al.; 2003). Pollard et al. (1991) indicated that the organic compounds tend to have a detrimental effect on the properties of cement material. Vipulanandan (1995) studied the effect of phenol on the setting of cement and remediation of contaminated soil by using the S-S technique. He showed that phenol retards the initial and final setting times of cement by interfering with normal cement hydration reactions. He also found from experimental tests that the compressive strength of treated contaminated soil decreased with higher phenol content but increased with curing time. Sora et al. (2002) studied the hydration and structure of methanol and 2-mono chloroaniline (2-MCA) and the leaching efficiency of 2-MCA from the dried structure after 28 days. Their results showed that a maximum of $75 \%$ of 2-MCA was released in the leachate solution. They indicated that the S-S technique is not suitable for that compound without using any adsorbent. Yilmaz et al. 
(2003) studied the effect of cement-clay pastes for S-S of 2 chloroaniline. They found that cement is unable to effectively immobilize these substances; organics interfere in a detrimental way with the cement hydration process and they are not firmly bound into the inorganic silicate (matrix of cement paste). Karamalidis and Voudrias (2007) studied the leaching behavior of hydrocarbon from oily refinery sludge samples that were stabilized and solidified with different percentages of cement. They stated that cement added to oily refinery sludge containing alkanes and PAHs led to higher concentration in leachates from batch extraction than were observed prior to $\mathrm{S}-\mathrm{S}$ treatment. It is resulted from previous research works that the S-S technique based on cement as binder is dependent on the type of organic contaminating compound, the concentration of contaminant, soil and percent of added cement. Karamalidis and Voudrias (2007) conducted stabilization/solidification tests on oil refinery sludge by using two types of cement (Portland cement and blended cements). The amount of cement used was between 10$70 \%$ of the weight of sludge. They concluded from the results of leaching tests that, by increasing the percent of the blended cement the concentration of phenathrene was not changed from the initial value $(0.005 \mathrm{mg} / \mathrm{kg})$. For the samples with $20 \%$ blended cement, the concentration of benzoperylene was nearly trace but there was an increase in the concentration by adding blender until $70 \%$ so, at $70 \%$ blender the concentration reached to $0.0081 \mathrm{mg} / \mathrm{kg}$. Therefore, the concentration of contaminant is dependent on the type and percent of binder. Vipulanan (1995) carried out leaching tests on samples of soilcement that were contaminated with 400, 1000 and $2000 \mathrm{mg} / \mathrm{kg}$ phenol and mixed with $20 \%$ cement at curing time of 28 days. He concluded that at a given time, the percent recovery of phenol for $2000 \mathrm{mg} / \mathrm{kg}$ is more than 1000 and $400 \mathrm{mg} / \mathrm{kg}$. 
Review of the literature shows that there are a number of research works on the effect of cement on the stabilization and solidification of contaminated soil. The achieved results are not the same; some of them report that using cement as a binder in S-S is useful and the results of some others are opposite. Therefore, the aim of this work is to evaluate the effect of cement on the stabilization and solidification of a clay soil contaminated with anthracene. The choice of this substance in this research was due to the existence of a number of pesticide production factories and plastic industry around the city of Karaj near Tehran that are a source of production of anthracene that has contaminated the ground.

The investigation is comprised of three stages. In the first stage, the mechanical behavior of a clay contaminated with $1200 \mathrm{mg}$ anthracene per $\mathrm{kg}$ of soil is studied and the results are compared with natural soil. In the second stage different percentages of cement (20 and $30 \%$ ) are added to natural and contaminated soil and the results are compared to study the effect of different cement contents on the mechanical behavior of contaminated soil for different amounts of contamination and different curing times. In the third stage, leaching tests are performed on samples of contaminated soil and contaminated soilcement using the HPLC (High-Performance Liquid Chromatography) apparatus. The concentration of released anthracene from soil and treated samples with different percentages of cement and curing times are compared and discussed.

\section{Materials and Methods}

The main materials that were used in this work were soil, cement and anthracene. The properties of these materials are described in this section.

\section{Soil}


The soil that was used in this experimental work was chosen to be a clay soil because the majority of production centers of pesticides and the plastic industry in the study area (Karaj city near Tehran) are founded on clay soil. The soil was obtained from a local seller and it was similar to the soil that the pesticide production factories and plastic industry are founded on it. The used soil was consisted of $23 \%$ sand, $52 \%$ silt and $25 \%$ clay. The specific gravity of solids $\left(\mathrm{G}_{\mathrm{s}}\right)$ was 2.71 . The liquid limit and plasticity index of the soil were $48.0 \%$ and $22.0 \%$. The results of standard compaction tests showed that the maximum dry unit weight and optimum water content of the clay were $17.78 \mathrm{kN} / \mathrm{m}^{3}$ and $18.0 \%$ respectively. According to the Unified Soil Classification System (USCS), the soil can be classified as clay with low plasticity (CL). XRD (X-ray diffraction) tests were conducted on samples of this soil. Based on the XRD tests the minerals of used soil were quartz, calcite, clay mineral, feldspar $(\mathrm{Na}, \mathrm{Ca})$ and fledspar $(\mathrm{K})$. The results also show the clay minerals of this soil were illite, chlorite and montmorillonite. The chemical properties of the soil are summarized in Table 1.

\section{Cement}

Portland cement type 1 was used in this study because of the frequency of its use and its relatively low cost and high availability. Other researchers such as Vipulanandan (1995) used Portland cement type 1 for stabilization and solidification a soil contaminated with phenol. The specific gravity and Blaine fineness of it were 3.15 and $4100 \mathrm{~cm}^{3} / \mathrm{g}$. Table 2 shows the physical and mechanical properties of the cement.

\section{Anthracene}

Anthracene is from a group of chemicals called polycyclic aromatic hydrocarbons (PAHs). Polycyclic aromatic hydrocarbons (PAHs) belong to the group of persistent 
organic pollutants which are relatively resistant to biodegradation and can remain in the environment for a long time (Maliszewska-Kordybach, 1999; Wild and Jones, 1995). PAHs present in soils may exhibit a toxic activity towards different biological elements of the environment such as plants, microorganisms and invertebrates (Jensen and FolkerHansen, 1995; Ren et al., 1996; Smreczak and Maliszewska- Kordybach, 1999; Maliszewska-Kordybach et al., 2000; Turek-Szytow, 2000 and Sverdrup, 2001). Anthracene can vary in appearance from a colorless to pale yellow crystal-like solid. Its chemical formula is $\mathrm{C}_{14} \mathrm{H}_{10}$ consisting of three fused benzene rings. Anthracene that was used in this work was a product of Merck Company. Its major applications can be found in dye, plastic industry as well as in pesticides production. Its molecular weight and density are $178.23 \mathrm{~g} / \mathrm{mol}$ and $0.7407 \mathrm{~g} / \mathrm{mL}$ respectively. It had melting and boiling points of $218^{\circ} \mathrm{C}$ and $340^{\circ} \mathrm{C}$. The dielectric constant and viscosity of it are 2.35 and $0.602 \mathrm{cp}$. The value of its water solubility at $25^{\circ} \mathrm{C}$ is $0.044 \mathrm{~g} / \mathrm{L}$ and its density at $20^{\circ} \mathrm{C}$ is $1.25 \mathrm{~g} / \mathrm{cm}^{3}$.

\section{Sample preparation}

For preparing contaminated soil with anthracene the desired weight of soil was spiked with anthracene at concentration of $1200 \mathrm{mg} / \mathrm{kg}$. Other researchers such as Chi et al. (2010 and 2011) and Delgado-Balbuena et al. (2013) used 200 and $500 \mathrm{mg} / \mathrm{kg}$ in their works. In this work it was decided to use $1200 \mathrm{mg} / \mathrm{kg}$ anthracene in order to better highlight its effects on the behavior of soil and soil-cement. Since its solubility in water is very low and it is completely dissolved in acetone (Eibes et al., 2005) therefore the mixture of acetone anthracene (10 $\mathrm{g}$ anthracene per one liter acetone) was subsequently mixed with the measured amount of soil. The soil-acetone-anthracene mixture was placed in a tray for nearly one week until the acetone completely evaporated and contaminated 
soil was dry. Static compaction was used for preparing the samples. Compaction was done in a special mould by applying a static pressure, using a loading machine. The dimensions of the mould used for preparing the samples for unconfined compression tests were $50 \mathrm{~mm}$ diameter and $100 \mathrm{~mm}$ length with detachable collars at both ends. For preparing different samples for unconfined compression tests, natural soil, contaminated soil, cement and water were weighted with accuracy of $0.1 \mathrm{~g}$. They were mixed with an amount of water corresponding to optimum water content. Samples were prepared by static compaction of the moist soil in the mould in three layers. Each layer was compacted to a defined vertical load at a fixed displacement rate of $1.5 \mathrm{~mm} / \mathrm{min}$ until the corresponding maximum dry unit weight due to compaction curve was achieved. The vertical load was the same for each layer but its value was dependent on the kinds of materials that were used for establishing the compaction curve. The load for each layer of materials was determined by trial and error. Before placing the next layer, the surface of the compacted layer was scarified so that there was good bond between adjacent layers of soil. The uncontaminated and contaminated soil-cement samples were stored in a curing cabinet at constant temperature and relative humidity according to the ASTM D1632-07 standard for curing times of $3,7,14$ and 28 days.

\section{Experimental tests}

The effectiveness of the treatments was assessed based on the unconfined compressive strength and leachability of contaminated samples.

Unconfined compression tests were performed on the prepared samples according to the ASTM D1633-07 standard. The rate of loading was selected as $1 \mathrm{~mm} / \mathrm{min}$ (as used by many researchers such as Kumar et al. 2007 and Estabragh et al. 2012 for mixtures of fly 
ash with clay and soil-cement respectively). The applied load was recorded continuously and the test was continued until failure of the sample was attained and the compressive strength of the sample was determined.

Leaching tests was conducted on the grounded contaminated soil and contaminated soilcement according to the USEPA (1992-1310b) method. Cylindrical samples of contaminated soil and contaminated soil-cement at desired curing time were grounded to the fine particles and deionized water was added to the grounded samples with the ratio of 16:1. The mixture was placed in an extractor and agitation was carried out for 24 hours. After that the mixture was put on a flat table until the settlement of particles was complete and the solid phase was separated from the liquid phase. The liquid phase was filtered through a $0.45 \mu \mathrm{m}$ membrane to remove suspended particles. The filtered liquid was then used for determination the amount of anthracene. HPLC (High-Performance Liquid Chromatography) apparatus was used for analysis of the liquid phase. It was a modular Shimadzu LC-10 system comprising of an LC-10AD pump, a CTO-10A column oven, a SPD-10A UV-DAD detector with wavelength of $274 \mathrm{~nm}$, a FLD detector, a CBM-10A interface and an LC-10 workstation. The HPLC apparatus was calibrated using external standards prior to performing the chemical analyses. A standard pure compound was injected to the apparatus and the peak in the chromatogram was assigned based on the retention time of the standard. The peak areas or heights are used to determine the concentration of released contamination from the sample. Comparing the response of the unknown concentration to that of the known (standard) concentration is used to find the amount of concentration in the released leaching liquid. 
Scanning electron microscopy (SEM) tests were performed on the samples in order to observe the microstructure of the samples in different conditions. The samples were prepared according to the optimum water content and maximum dry unit weight. A curing time of 7 days was considered for the samples of soil-cement and the cementtreated contaminated soil.

\section{Results}

Fig.1 shows the results of compaction tests for the natural soil, soil contaminated with anthracene, uncontaminated and contaminated mixtures of soil-cement with $20 \%$ and $30 \%$ cement. As shown in this figure the optimum water content and maximum dry unit weight of the natural soil are $18.0 \%$ and $17.78 \mathrm{kN} / \mathrm{m}^{3}$ and they are changed to $19.6 \%$ and $17.0 \mathrm{kN} / \mathrm{m}^{3}$ for the contaminated soil. It is shown that the effect of anthracene is increase in the optimum water content and decrease in the maximum dry unit weight. The results for the mixtures of soil-cement with $20 \%$ and $30 \%$ cement show that the effect of $20 \%$ cement on the variation of optimum water content and maximum dry unit weight is not significant in comparison with the natural soil. However, adding $30 \%$ cement changes the optimum water content and maximum dry unit weight to $17.23 \%$ and $18.4 \mathrm{kN} / \mathrm{m}^{3}$ respectively.

The stress-strain curves for the natural soil, contaminated soil, uncontaminated soilcement and contaminated soil-cement at curing time of 7 days are shown in Fig.2. The results show that the final strength of the natural soil is $392.7 \mathrm{kPa}$ at $2.16 \%$ strain and for the contaminated soil they are changed to $164.35 \mathrm{kPa}$ at $2.9 \%$ strain. It is observed from Fig. 2 so the failure of the natural soil is at $2.1 \%$ strain but that of the contaminated sample is at $2.9 \%$ strain. Comparison of these strains shows that the ductility of the 
contaminated soil is higher than the natural soil. The results for the uncontaminated soilcement with $20 \%$ and $30 \%$ cement (Fig.2) show that the final strengths of the samples with $20 \%$ and $30 \%$ cement are 3510.8 and $3954.1 \mathrm{kPa}$ respectively. It is resulted that strength is increased in comparison with the natural soil and this increase is dependent on the percent of cement; the higher the percent of cement, the greater is the strength achieved. These results also show that by adding cement to the soil its brittle behavior is increased. The stress-strain curves of the contaminated soil-cement at 7 days curing time are shown in Fig.2. As shown in this figure the final strengths of the samples with $20 \%$ and $30 \%$ cement are 1957.4 and $2904.3 \mathrm{kPa}$ at strains of 1.34 and $1.2 \%$ respectively. Therefore, adding cement to the contaminated soil increases the strength and reduces the ductility of the samples in comparison with the contaminated soil.

Fig.3 shows the final strength of the uncontaminated and contaminated soil-cement samples for different curing times $(3,7,14$ and 28 days). As shown in this figure the strength of the contaminated soil-cement with $20 \%$ cement is $1608.9 \mathrm{kPa}$ at 3 days curing time and it changes to $2348.5 \mathrm{kPa}$ after 28 days curing time. This trend is also observed for the contaminated soil-cement with $30 \%$ cement and uncontaminated soil-cement samples. It can be concluded that for a constant percent of cement the strength is increased with increasing the curing time (Estabragh et al., 2016, Tang et al., 2007 and Bahar et el., 2004). The results show that the increase in strength for the natural soil mixed with $20 \%$ cement, in comparison with the strength at 3 days curing time, is 31.5 , 38.5 and $49.6 \%$ for curing times of 7,14 and 28 days. These values are $22.4,33.0$ and $49.6 \%$ for the soil mixed with $30 \%$ cement. A similar trend is observed for the contaminated soil mixed with cement: for $20 \%$ cement, the increase in strength at curing 
times of 7,14 and 28 is $21.7,32.3$ and $46.0 \%$. The increase in strength for contaminated soil mixed with $30 \%$ cement are $37.8,53.5$ and 64.0 at curing times of 7,14 and 28 days respectively. The results in Figs 2 and 3 show that the strength of the contaminated soil is increased by adding cement in comparison with the contaminated soil but it is less than the uncontaminated soil-cement at constant percent of cement and curing time.

Fig. 4 shows typical results of leaching tests that were obtained from the HPLC apparatus for the contaminated soil-cement with $20 \%$ and $30 \%$ cement at 28 days curing time. Based on these results the concentration of released anthracene per $\mathrm{kg}$ was calculated for specific percents of cement and curing times. As shown in Fig.5 adding cement to the contaminated soil caused the concentration of released anthracene to decrease. The results show that this reduction is dependent on the percent of cement. For curing time of 7 days the concentrations of anthracene are 0.215 and $0.13 \mathrm{mg} / \mathrm{kg}$ for samples with $20 \%$ and $30 \%$ cement. It is seen that by increasing the percent of cement the concentration of anthracene is reduced nearly by $40 \%$. The results also show that for a specific percent of cement, increasing the curing time causes reduction in the concentration of anthracene. For sample with $30 \%$ cement at curing time of 7 days the concentration of anthracene was $0.13 \mathrm{mg} / \mathrm{kg}$ but after 28 days curing time it was changed to $0.04 \mathrm{mg} / \mathrm{kg}$. This shows that increasing both curing time and percent of cement is important in reduction of anthracene after leaching. The World Health Organization/International Program on Chemical Safety (WHO/IPCS) indicated (1988) that the acceptable level of PAHs (Poly Aromatic Hydrocarbon) components in soil is between $1-3 \mathrm{mg} / \mathrm{kg}$. Anthracene is from the PAHs group. Comparing the results of the leaching tests $(0.055$ and $0.04 \mathrm{mg} / \mathrm{kg}$ for soilcement samples with 20 and $30 \%$ cement at curing time of 28 days) with the 
recommended value by WHO/IPC shows that it is within the acceptable level. It can be resulted that if this leaching liquid enters the soil, the contaminated soil would not be harmful to the environment.

\section{Discussion}

Clay particle surfaces carry negative charges (Mitchell and Soga, 2005 and Craig, 2004). They attract cations in order to neutralize the unbalanced negative charges between the surfaces of clay particles. The cations are adsorbed onto the clay surface and held by a strong and tight bond. In addition, to these cations, there are some charges (cations and anions) that are produced from solution of different precipitated salts between particles (Mitchell and Soga, 2005). Water and soil interact with each other due to the polarity of molecules of water. The interaction is through sorption of molecules of water to the surface of particles. These interactions affect the physical and physicochemical behavior of the mixture. When water is added to dry clay particles these ions (cation and anions) go to solution. The desorbed cations have a tendency to diffuse away from the surface of particles to attain an equalized concentration. This displacement of cations is prevented by the negative electric field of the surface of clay particles. This leads to the formation of a liquid layer that is composed of ion distribution in suspension in the vicinity and around clay particles. The concentration of ions is reduced with increasing the distance from particle surface until it obtains the behavior similar to bulk water. This system that consists of distributed ions along with charge surface is called Diffuse Double Layer (DDL) (Craig, 2004). The thickness of DDL is dependent on the electrolyte concentration, cation valence, dielectric constant, temperature, size of ions, $\mathrm{pH}$, clay platelet associations and particle interference. Using the DDL theory, the effect of factors 
such as cation valance, dielectric constant, electrolyte concentration and temperature on the thickness of DDL can be readily be determined (Mitchell and Soga, 2005). Ion exchange can occur between the ions in Diffuse Double Layers and the surfaces of the reactive soil particles due to the charge imbalance. The exchange reactions consist of replacement of a part or all of the adsorbed ions of one type by ions of another type. Isomorphous substitution is the main source of clay exchange capacity where cations with higher valance are replaced with lower valance cations and larger cations replace smaller cations of the same valence. These cations that are attached to the clay surface by replacement are termed exchangeable cations (Craig, 2004). The quantity of exchangeable cations held by the soil is termed the cation-exchange capacity (CEC) (Mitchell and Soga, 2005). The substitution of one type of cation by another type depends on many factors including valence and ion size.

The structure of soil is changed with the variations in the thickness of DDL, so, shrinking of this layer causes a flocculated structure in the soil (Mitchell and Soga 2005, Ratnaweera and Megooda 2006 and Estabragh et al. 2016).

Fang (1997) indicated that chemical reactions between contaminants and soil are dependent on the phase of the compound, speciation, mineralogy, $\mathrm{pH}$ and organic content. Understanding the interaction between soil and contaminants is a guide for assessing the influence on human life and environment (Jone, 2010). This information is important for choosing the best method for in-situ remediation of soil. Bone et al. (2004) stated that the main reactions between contaminants, pore water and soil occur through chemical reactions including sorption, oxidation, reduction, precipitation, etc. Sorption is the primary mechanism for partitioning of solutes between the liquid phase and solid particle interfaces (Jone, 2010). The interaction forces in sorption are chemical forces such as 
covalent and electrostatic forces. The adsorption of contaminant to the soil particles is termed surficial attachment (Yong, 2001). Adsorption is divided into physical and chemical groups. Physical adsorption is defined as contaminant in pore water being attached to the soil particle surface due to the charge deficiency. Physical adsorption is due to the van der Waals forces and is know as low energy adsorption (Jone, 2010). Chemical adsorption or chemisorption refers to specific adsorption and occurs through covalent bonding. The nature of chemical adsorption is such that higher adsorption energies are obtained in these reactions. Lagaly (1984) stated that the interaction between organic matter and clay is due to penetration of organic matter between silicate layers of clay soil. He indicated that the adsorption of organic compounds onto the clay particle surfaces depends on the availability of the surface, ability of organic molecule to displace water molecules to clay surface by van der Waals forces and intercalation. The chemical adsorption makes strong and permanent bonds between clay surface and organic contaminant that is stronger than physical adsorption. The important factors that affect adsorption of organic matters by soil particles are the nature of the functional group in the molecule, shape, size, configuration, polarity and water solubility (Mitchell and Soga, 2005). However, the interaction between clay and organic compound is important in Geotechnical and Geoenvironmental Engineering because of migration of contaminant. Various PHCs (Petroleum Hydrocarbon Compounds) such as anthracene are primarily formed by non-polar organic compounds with low dipole moments (generally less than one) and constant dielectric less than three (2.35). Adsorption of non-ionic organic compounds by soil fractions is governed by the $\mathrm{CH}$ activity of molecule (Yong, 2001). The chemical structures of petroleum hydrocarbons such as monocyclic aromatic 
hydrocarbons and polycyclic aromatic hydrocarbons (PAHs) are in loops of ring shape. They usually have not electron-withdrawing units such as $\mathrm{C}=\mathrm{O}$ and $\mathrm{C}=\mathrm{N}$ associated with the molecules. According to the PAH the PHC molecules would be weakly adsorbed (mainly by Van der Waals adsorption) by the soil and do not involve any strong ionic interaction with different soil particles. Therefore, non-polar compounds (PHCs) develop different reaction and bonding relationship with surface of soil particles. Weakly polar compounds are more readily adsorbed onto soil surface in contrast to non-polar compounds. The adsorption of non-polar compounds onto soil surfaces is dominated by weak bonding (London-van der Waals attraction) and is generally restricted to external soil surface, primarily because of their low dipole moments (less than one) and their low dielectric constants (less than three). On the other hand, aqueous solubility and partition coefficients are important factors in controlling the interactions of organic compounds with soil particles (Yong, 2001)

The results of compaction curve (Fig.1) for anthracene-contaminated soil show that its maximum dry unit weight is less and optimum water content is more than the natural soil. This may be due to the decrease in the thickness of the diffuse double layer that leads to the flocculated structure. Forces of repulsion and attraction act between adjacent clay mineral particles. Repulsion occurs between the like charges of double layers and it is dependent on the characteristics of the layers. An increase in cation valance or concentration will result in a decrease in the value of van der Waals forces that are independent of double layer characteristics. They are decreased with increasing the distance between particles. The net amounts of inter-particle forces influence the structure of the soil. If there are net attraction forces, the orientation of the particles tend 
to be edge-to-face or edge-to-edge. This form of structure is referred to as flocculated structure (Craig, 2004). So the degree of flocculation in the anthracene-contaminated soil is more than the natural soil. Since the energy that was used for compaction is the same as the energy that was used for natural soil, it can be said the energy that was used for contaminated soil was enough because of the high degree of flocculation and it resulted in low maximum dry unit weight and high optimum water content in comparison with the natural soil. As shown in Fig.1, adding 30\% cement to the natural soil causes a decrease in optimum water content and an increase in maximum dry unit weight. But the effect of adding $20 \%$ cement is not considerable. It can be concluded that adding $30 \%$ cement to the soil results in pasting of the particles together and formation of relatively coarse particles. This in turn causes decrease in optimum water content and increase in maximum dry unit weight. Adding of $20 \%$ cement may not be enough for pasting the particles or the bond between the particles would be weaker.

Figs 2 and 3 show that strength of natural soil is $392.7 \mathrm{kPa}$. By adding 20 and $30 \%$ cement the final strength at 7 days curing time is changed to 3510.8 and $3954.1 \mathrm{kPa}$ respectively. These figures show that the final strength of contaminated soil is $164.35 \mathrm{kPa}$. By mixing with 20 and $30 \%$ cement the strength for 7 days curing time reached to 1957.4 and $2904.3 \mathrm{kPa}$ respectively. It is resulted that by adding cement to the contaminated soil the strength of it is increased. Comparing these results with strength of natural soil with the same percent of cement and curing time shows reduction in the final strength. It is resulted from Fig. 3 that the strength of the contaminated soil mixed with $20 \%$ cement at curing times of $3,7,14$ and 28 days shows reductions of $39.5,44.0,42.0$ and $41.9 \%$ respectively in comparison with the natural soil mixed with cement. For the contaminated 
soil with $30 \%$ cement, at the same curing times these reductions are 35.0, 27.0, 25.0, and $28.0 \%$ in comparison with the uncontaminated soil with $30 \%$ cement. When cement is mixed with a clay soil, the cement is encountered with pore water between the particles of soil and the hydration of cement occurs rapidly. The hydration occurs between water and tricalcium silicate $\left(\mathrm{C}_{3} \mathrm{~S}\right)$, dicalcium silicate $\left(\mathrm{C}_{2} \mathrm{~S}\right)$ and tricalcium aluminate $\left(\mathrm{C}_{3} \mathrm{~A}\right)$. The major hydration products of $\mathrm{C}_{3} \mathrm{~S}$ are hydrated calcium silicates $\left(\mathrm{C}_{3} \mathrm{~S}_{2} \mathrm{H}_{3}\right)$, hydrated calcium aluminate $\left(\mathrm{C}_{3} \mathrm{AH}_{6}\right)$ and hydrated lime $\left(\mathrm{Ca}(\mathrm{OH})_{2}\right)$. Hydrated lime is dissociated into $\mathrm{Ca}^{2+}$ and $\mathrm{OH}^{-}$due to some reactions and they modify the electrical surface forces of the clay structure. The change in the soil structure is a consequence of cation exchange of monovalent alkali ions by dissociating divalent calcium ions in the pore water. This results in flocculation of clay particles and reduces the plasticity and increases the strength and stiffness of the clay soil. Hydrated calcium silicates $\left(\mathrm{C}_{3} \mathrm{~S}_{2} \mathrm{H}_{3}\right)$ and hydrated calcium aluminate $\left(\mathrm{C}_{3} \mathrm{AH}_{6}\right)$ are cementation products. In addition, the hydration of cement leads to an increase in the value of $\mathrm{pH}$ of the pore water. The strong bases dissolve the silica and alumina from clay minerals. The hydrous of silica and alumina will then gradually react with calcium ions liberated from the hydrous of cement to form insoluble compounds such as calcium silicate hydrate (CSH) and calcium aluminate hydrate $(\mathrm{CAH})$. This secondary reaction is known as the pozzolanic reaction. These gels bind the soil particles and change them to a solid condition. In the pozzolanic reaction chemical bonds develop between adjacent cement grains surfaces and interfaces between cement grains and soil particles. In cohesive soils cement hydration develops strong linkages between the minerals and the aggregates to form a honeycomb type structure whereby the particles of soil can no longer slide over each other (Chew et al., 2004). 
Therefore, not only cement reduces the plasticity of soil, but it also increases the strength and reduces the water holding ability of cohesive soils (Tang et al., 2007 and Estabragh et al., 2016 and 2017). The majority of organic compounds retard or inhibit the setting and curing of the final products in the S-S process. Non-polar organic matters such as oils and grease inhibit the setting of cement in this treatment. Lea (1970) stated that the retarding effect may be due to the non-ionized $(\mathrm{OH})$ group that is adsorbed by bonding to the surface of cement particles. He indicated that the greater the number of $\mathrm{OH}$ groups per molecule, the greater is the possibility of adsorption and hydration. Generally polar organics have little effect on setting although some alcohols may retard setting (Conner, 1990). Therefore, in this case the anthracene, via formation of a protective film around the soil particles, prevents from reaction of some soil particles with hydrated production and hence the strength is reduced in comparison with uncontaminated soil-cement.

Fig.5 shows that the concentration of the released anthracene in the contaminated soil is $0.294 \mathrm{mg} / \mathrm{kg}$. This indicates that the majority of anthracene was adsorbed by clay particles of the soil or was precipitated between the particles due to chemical reactions. Adding of cement to the contaminated soil causes a reduction in the concentration of anthracene. This reduction is dependent on the percent of cement and curing time. The higher the percent of cement and curing time, the higher is the reduction in concentration of anthracene (Fig.5). This observation suggests that the mechanism responsible for removal or encapsulation of anthracene is dependent on time and percent of cement. This time dependent behavior of anthracene is difficult to explain as it may be the result of several concurrent and counteracting phenomena such as degradation desorption from clay minerals and encapsulation of the compounds. Karamalidis and Voudrias (2007) 
used the encapsulation phenomenon to describe the effect of stabilization and solidification on oily refinery sludge. The subsequent decrease of concentration observed in some cases suggests that progressively tighter encapsulation of the compounds in the clay aggregates (produced by pozzolanic reactions) may become dominant after longer curing time and with increasing the percent of cement. Fig.6 shows the microstructure of natural soil, contaminated and soil-cement and stabilized of contaminated soil with 20 and $30 \%$ cement for curing times of 7 days. It can be observed in Fig.6a that the fabric of natural soil is flocculated. By contaminated this soil with anthracene the particles changed to sheet form and the fabric of soil is flocculate by reduction in the space between the particles (Fig.6b). This condition can be attributed to the adsorb of anthracene by soil and changing the ions of soil particles. Figs. $6 \mathrm{c}$ and $\mathrm{d}$ show the microstructure of soil stabilized with 20 and $30 \%$ cement for 7 days curing time. The reticulate and needle shape products are observed in these figures. They are C-S-H and ettringite respectively as reported by Bensted and Barnes (2002). It can be seen that by increasing the percent of cement in the stabilized natural soil with cement and the morphology of C-S-H and ettringite is well developed so, the quality of them is relatively large. This shows the flocculated nature of the fabric in the matrix of stabilized soil samples. The flocculated fabric can be attributed to the cation exchange process that results in replacement of calcium ions with exchangeable ions such as potassium and sodium (Chew et al., 2004). The formation of reticulate and needle shaped hydration products which occupy the large pres and enhance cementation bonding of soil particles (Chew et al., 2004). Figs.6e and f show the microstructure of stabilized soil with 20 and $30 \%$ cement at 7 days curing time is not the same as stabilized natural soil (Figs. 6c and 
d). The production of reticulate and C-S-H are not developed as for stabilized natural soil so, the presence of small amount of these products can be seen. The pores between particles are less than stabilized natural soil and this reduction is increased with increasing the percent of cement. It can be said that capsulation of anthracene is formed between the particles hence the space between them is reduced. It can be observed from theses figures (Figs.6e and f) that the surfaces of clay particles are nearly covered by anthracene.

\section{Conclusion}

The stabilization and solidification technique was investigated through experimental tests on remediation of a clay soil contaminated with anthracene. The results showed that this technique is an effective method for decreasing the concentration and mobility of anthracene in leaching. It was also shown that the strength of the soil is increased and leaching of anthracene to the environment is decreased. The following conclusions can be drawn from this study:

- The strength of contaminated soil is increased more than $100 \%$ by adding cement and the amount of increase is a function of percent of cement and curing time. For a given curing time, the amount of increase in strength is less for the contaminated soil-cement than the uncontaminated soil-cement. The average amounts of increase in strength for the uncontaminated soil are 71.5 and $40 \%$ in comparison the contaminated soil with 20 and $30 \%$ cement at different curing times

- Concentration of leaching liquid is decreased by adding cement to the contaminated soil. The decrease in concentration during leaching is dependent on the percent of cement and curing time; for $20 \%$ cement the amount of reduction was $7.8,27.1,64.7$ and $83 \%$ for 
curing times of $3,7,14$ and 28 days respectively. For $30 \%$ cement content, the reduction at the same curing times was $23.4,56.3,70.5$ and $86.4 \%$ respectively. 


\section{References}

Antemir, A., Hills, C.D., Carey, P.J., Magnié, M.C. and Polettini, A. (2010). "Investigation of 4-years old stabilised/solidified and accelerated carbonated contaminated soil.” J. Hazard. Mater. 18(1-3), 543-555.

ASTM (2007 ). 's Standard practice for making and curing soil-cement compressive and flexure test specimens in the laboratory." D1632, west Conshohocken, PA.

ASTM ( 2007 ). "Standard test method for compressive strength of moulded soil- cement cylinders "D1633, west Conshohocken, PA

Bahar, R., Benazzoug, M., and Kenai, S. (2004). 'Performance of compacted cement stabilized soil.', Cem. Concr. Compos., 24(7),811-820.

Bensted, J. and Barnes, P. (2002). "Structure and performance of cements." Spon Press, New York, USA.

Bettahar, M., Ducreax, J., Schafer, G. and Van Dorpe, F. (1999). "Surfactant enhanced in situ remediation of LNAPL contaminated aquifers: Large scale studies on a controlled experimental site." Transport Porous Med. 37 (3), 255-76.

Bishop, P.L. (1990). "Solidification/Stabilization of Contaminated Soils-An Overview." Proc. Conf. on Contaminated Soil, 10-14 December, Karlsruhe, Federal Republic of Germany, 1265-1274. 
Bone, B. D., Barnard L. H. and Hills C. D. (2004). "Guidance on the use of Stabilisation /Solidification for the Treatment of Contaminated Soils." Science report: SC980003/SR

Botta, D., Dotelli, G., Biancardi, R., Pelosato, R. and Sora, N.I. (2004). “Cement-clay pastes for stabilization/solidification of 2-chloroaniline.” Waste. Manage. 24, 207216.

Cai, Y., Shi, B., Ng, C.W.W. and Tang, C-S. (2006). "Effect of polypropylene fiber and lime admixture on engineering properties of clayey soil.” Eng. Geol. 87, 230-240.

Chandra, S. and Flodin, P. (1987). "Interactions of polymers and organic admixtures on Portland cement hydration." Cem. Conc. Res. 17, 875-890.

Chen, Q.Y., Tyrer, M., Hills, C.D., Yang, X.M. and Carey, P. (2009). "Immobilization of heavy metal in cement-based solidification/stabilization: A review." Waste Manage. 29(1), 390-403.

Chew, S.H., Kamruzzaman, A.H.M. and Lee, F.H. (2004). "Physicochemical and engineering behavior of cement treated clays." J. Geotech. Geoenviron. Eng. 130(7), 696-706.

Chi, F-H., Leu, M-H. and Lee, R-C. (2010). "Removal of anthracene contaminated soil using soybean oil.” Sustain. Environ. Res. 20(5), 275-280.

Chi, F-H., Lou, M.-H., Tsao, C-W. and Shiu, G-C. (2011). "Removal of anthracene contaminated soil using micro-emulsified solvent and mixed surfactant.” Sustain. Environ. Res. 21(3), 181-186.

Collins, K. and McGown, A. (1974). "The form and function of microfabric features in a variety of natural soils." Geotechnique. 24 (2), 223-254. 
Conner, J.R. (1990). "Chemical fixation and solidification of hazardous wastes." Van Nostrand Reinhold.

Conner, J.R. (1993). "Chemistry of cementitious solidified/stabilized waste form in chemistry and microstructure of solidified waste forms." CRC/Lewis, Boca, Rato, FL., 41-82.

Craig, R.F. (2004). "Carig's Soil Mechanics." Seventh Edition, Taylor \& Francis, London, UK.

Delgado-Balbuena, L., Aquilar-Chàvez. A.R., Luna-Guido, M.L. and Dendooven, L. (2013). "Mixing of an anthracene-contaminated soil: a simple but efficient remediation technique?" Ecotoxicol. Environ. Saf. 96(1), 238-241.

Donnelly, J. and Webster, W. (1996). "From sediment to solid.” Civil Eng.—ASCE 66 (5), 41-43.

Du, Y.J., Jiang, N.J., Shen, S.L. and Jin, F. (2012). "Experimental investigation of influence of acid rain on leaching and hydraulic characteristics of cement based solidified/stabilized lead contaminated clay." J. Hazard. Mater. 225-226c, 195201.

Edmeades, R.M. and Hewlett, P.C. (1998). "Cement mixtures.” In Leas's chemistry of cement and concrete, $4^{\text {th }}$ ed. Edited by P.C. Hewlett, Butterworth-Heinemann, UK, 841-905.

Eibes, G., Cajthaml, T., Moreira, M.T., Feijoo, G. and Lema, J.M. (2005). "Enzymatic degradation of anthracene, dibenzothiophene and pyrene by manganese peroxidase in media containing acetone." Chemosphere. 64(3), 408--414. 
Estabragh, A.R., Namdar, P. and Javadi, A.A. (2012). "Behavior of cement-stabilized clay reinforced with nylon fiber." Geosynth. Int. 19(1), 85-92.

Estabragh, A.R., Khatibi, M. and Javadi, A.A. (2016). "Effect of cement on treatment of a clay soil contaminated with glycerol." J. Mat. Civ. Eng. 28(4),

Estabragh, A.R., Ranjbari, S, and Javadi, A.A. (2017). "Properties of a clay soil and soi cement reinforced with polypropylene fibers.” ACI, Mat. J. 114(2), 195-205.

Fang, H.Y. (1977), 'Introduction to environmental geotechnology,' CRC Press, Boca Raton, Fla.

Gussoni, M., Greco, F., Bonazzi, F., Vezzoli, A., Botta, D., Dotelli, G., Natali Sora, I., Pelosato, R. and Zetta, L. (2004). "HNMR spin-spin relaxation and imaging in porous system: an application to the morphological study of white Portland cement during hydration in the presence of organics." Magn. Resonance Imaging. 22, 877-889.

Jensen, J. and Folker-Hansen (1995). Soil quality criteria for selected organic compounds. Working report no.47, Danish Environmental Protection Agency.

John, U.E. (2010)." Chemical performance of cement stabilized contaminated clay." $\mathrm{PhD}$ thesis, University of Birmingham, Birmingham, UK.

Karamalidis, A.K. and Voudrias, E.A. (2007). “Cement-based stabilization/solidification of oil refinery sludge: Leaching behavior of alkanes and PAHs.” J. Hazard. Mater. $148,122-135$.

Kogbara, R.B. and Al-Tabbaa, A. (2011). "Mechanical and leaching behaviour of slagcement and lime activated slag stabilized/solidified contaminated soil." Sci. Total Environ. 409(11), 2325-2335. 
Kumar, A., Walia, B.S. and Bajaaj, A. (2007). "Influence of fly ash, lime and polyester fibers on compacted and strength properties of expansive soil." J. Mat. In. Civil Eng. 19(3), 242-248.

Lea, F.M. (1970). “The chemistry of cement and concrete.” E. Arnold, London.

Lagaly, G. (1984). "Clay - Organic interactions." Philosophical Transactions of the Royal society of London. A 311, $315-332$.

Lagaly G., Ogawa M. and Dekany I., (2006) "Clay mineral organic interaction", Handbook of clay science. Bergaya F, Theng BKG, Lagaly G (eds.) Vol.1, Chapter 7.3, 309-377.

Leonard, S. A. and Stegemann, J.A. (2010). "Stabilization/solidification of petroleum drill cuttings." J. Hazard. Mater. 174 (1-3), 463 - 472.

Liu, S.Y., Du, Y.J., Yi, Y.L. and Pulpora, A. (2012). "Field investigation on performance of T-shaped deep mixed columns over soft ground." J. Geotech. Geoenviron. Eng. 138(6), 718-727.

Maliszewska-Kordybach, B. (1999). "Sources, Concentrations, Fate and Effects of Polycyclic Aromatic Hydrocarbons (PAHs) in the Environment. Part A: PAHs in Air.” Pol. J. Environ. Stud. 8(3), 131-136

Maliszewska-Kordybach, B. and Smreczak, B. (2000). "Ecotoxicological activity of soils polluted with polycyclic aromatic hydrocarbons (PAHs) - Effect on plants." Environ. Technol. 21, 1099-1110.

Mitchell, J. K. and Soga, K. (2005). "Fundamentals of Soil Behaviour." Third Edition. John Wiley \& Sons, Inc. New York. 
Montgomery, D.M., Sollars, C.J., Perry, R., Tarling, S.E., Barnes, P. and Henderson, E. (1991a). "Treatment of organic - contaminated industrial wastes using cement-based stabilization/solidification-I. Microstructural analysis of cement-organic interactions." Waste. Manage. Res. 9, 103-111.

Paria, S. and Yuetl, P.K. (2006). "Solidification-stabilization of organic and inorganic contaminants using Portland cement: A literature review." Environ. Rev. 14(4), $122-135$.

Pollard, S.J.T., Montggomery, D.M., Sollars, D.M. and Perry, R. (1991). "Orgainc compounds in the cement-based stabilization/solidification of hazardous mixed wastes-mechanistic and process considerations." J. Hazard. Mater. 28, 313-327.

Ratnaweera, P. and Meegoda, J.N. (2006). "Shear strength and stress-strain behavior of contaminated soild." Geotech. Test. J. 29(2), 133-140.

Ren, L., Zieler, L. F., Dixon, D. G. and Greenberg, B. M. (1996). "Photo-induced effects of polycyclic aromatic hydrocarbons on Brassica napus (Canola) during germination and early seedling development." Ecotox. Environ. Safety. 33, 73-80.

Smreczak, B. and Maliszewska-Kordybach, B. (1999). "Effects of PAHs and Heavy Metals on Activity of Soil Microflora." in J. C. Block, V. V. Goncharuk and Ph. Baveye (eds), Bioavailability of Organic Xenobiotics in the Environment, NATO ASI Series, Kluwer Academic Publishers, Dordrecht, Boston, London, 377-380.

Sora, I.N., Plosato, R., Batto, D. and Dotelli, G. (2002). "Chemistry and microstructure of cement pastes admixed with organic liquids." Journal European Ceramic society, 22, 1463-1473. 
Sverdrup, L. E. (2001). "Toxicity of Tar Constituents in Terrestrial Ecosystem. Effects of Eight Polycyclic Aromatic Compounds on Terrestrial Plants, Soil Invertebrates and Microorganisms." Ph.D Thesis, Faculty of Mathematics and Natural Sciences, University of Oslo.

Tang, C., Shi, B., Gao, W., Chen, F. \& Cai, Y. (2007). "Strength and mechanical behaviour of short polypropylene-fiber reinforced and cement stabilized clayey soil." Geotextiles and Geomembrane, 25, 194-202.

Tremblay, H., Duchesne, J., Locat, J. and Leroueil, S. (2002). "Influence of the nature of organic compounds on fire soil stabilization with cement." Can. Geotech. J. 39(3), 535-546.

Turek-Szytow, J. (2000). "Kontrola $i$ ocena wplywu wielopier'scieniowych weglowodorów aromatycznych (WWA) na proces rekultywacji gleb zanieczyszczonych tymi zwia zkkami." Ph.D. Thesis, Politechnika S' la ska, Gliwice.

USEPA (1992)." Extraction Procedure (EP) Toxicity Test Method and Structural Integrity Test.” 1310b,Publication SW-846: Test Methods for Evaluating Solid Waste, Physical/Chemical Methods. Washington DC.

Vipulanandan, C. (1995). "Effect of clays and cement on the solidification/stabilization of phenol-contaminated soils." Waste. Manage. 15, 399-406.

Wild, S. R. and Jones, K. C. (1995). "Polynuclear aromatic hydrocarbons in the United Kingdom environment: A preliminary source inventory and budget." Environ. Pollut. $88,91-108$.

Wiles, C.C. (1987). "A review of stabilization/solidification Technology." J. Hazard. Mater. 14,5-21. 
World health organization/ international program on chemical safety (WHO/IPCS) (1988). "Selected non-heterocyclic polycyclic aromatic hydrocarbons. Environmental health criteria;" No. 202, Geneva: World Health Organization

Yilmas, O., ÜnIü, K. and Cokca, E. (2003). "Solidification/stabilization of hazardous wastes containing metals and organic contaminants.” J. Environ. Eng. 129, 366-376.

Yong RN. (2001). “Geoenvironmental Engineering, Contaminated soils Pollutant fate and Mitigation." CRC Press. 
Table 1. Chemical composition of soil

\begin{tabular}{|l|c|l|c|}
\hline $\begin{array}{l}\text { Chemical } \\
\text { component }\end{array}$ & Amount & $\begin{array}{l}\text { Chemical } \\
\text { component }\end{array}$ & Amount \\
\hline $\mathrm{pH}$ & 7.8 & $\mathrm{Mg}^{2+}(\mathrm{meq} / \mathrm{L})$ & 11.25 \\
\hline $\mathrm{EC}^{\mathrm{a}}(\mathrm{dS} / \mathrm{m})$ & 13.2 & $\mathrm{Cl}^{-}(\mathrm{meq} / \mathrm{L})$ & 62.5 \\
\hline $\mathrm{Na}^{+}(\mathrm{meq} / \mathrm{L})$ & 108.69 & $\mathrm{CO}_{3}^{2-}(\mathrm{meq} / \mathrm{L})$ & 0.6 \\
\hline $\mathrm{K}^{+}(\mathrm{meq} / \mathrm{L})$ & 0.20 & $\mathrm{HCO}_{3}{ }^{-}(\mathrm{meq} / \mathrm{L})$ & 5.0 \\
\hline $\mathrm{Ca}^{2+}(\mathrm{meq} / \mathrm{L})$ & 35.0 & $\mathrm{SO}_{4}{ }^{2-}(\mathrm{meq} / \mathrm{L})$ & 72.91 \\
\hline $\mathrm{Ca} \mathrm{CO}_{3}(\%)$ & 10.2 & O.C. ${ }^{\mathrm{b}}(\%)$ & 0.11 \\
\hline & & C.E.C. ${ }^{\text {c }}(\mathrm{meq} / 100 \mathrm{~g})$ & 8.42 \\
\hline
\end{tabular}

a-Electrical Conductivity

b- Organic Content

c- Cation Exchange Capacity 
Table 2. Physical and mechanical properties of cement

\begin{tabular}{|l|c|c|}
\hline Properties & Standard Designation & Value \\
\hline Normal consistency (\%) & ASTM C 187-10 & 29.2 \\
\hline Primary setting time (min) & ASTM C 191-08 & 108 \\
\hline Final setting time (min) & ASTM C 191-08 & 180 \\
\hline Compressive strength & & \\
(MPa) & ASTM C 109-08 & 23 \\
7days & & 34 \\
28 days & & 1.6 \\
\hline Tensile strength $(\mathrm{MPa})$ & ASTM C 190-85 & 2.4 \\
7 days & & \\
28 days & & 3.1 \\
\hline Flexure strength $(\mathrm{MPa})$ & & 4.2 \\
7 days & & \\
28 days & & \\
\hline
\end{tabular}




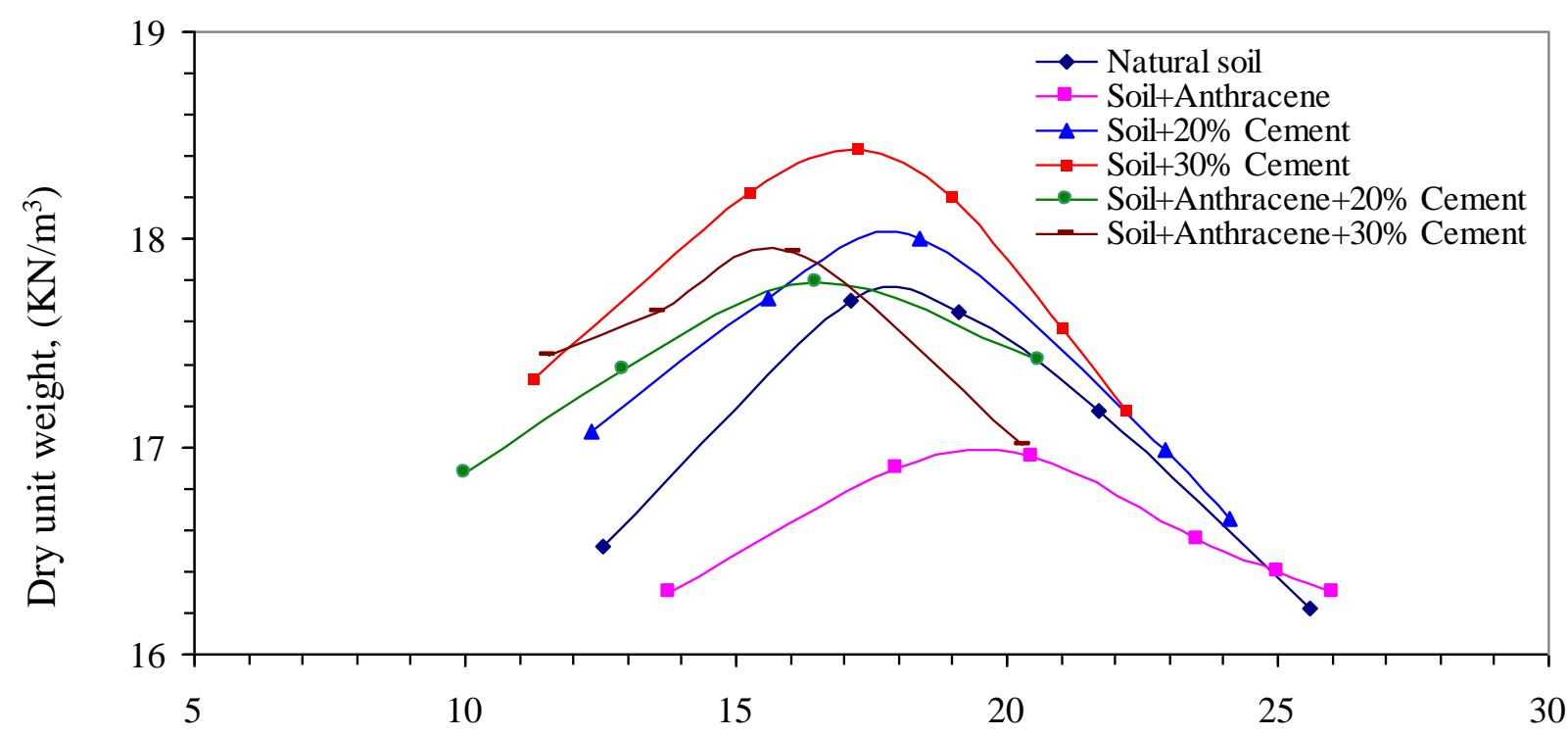

Water content, $w(\%)$

Fig.1 Compaction curves for natural soil, contaminated soil, uncontaminated and contaminated soil-cement

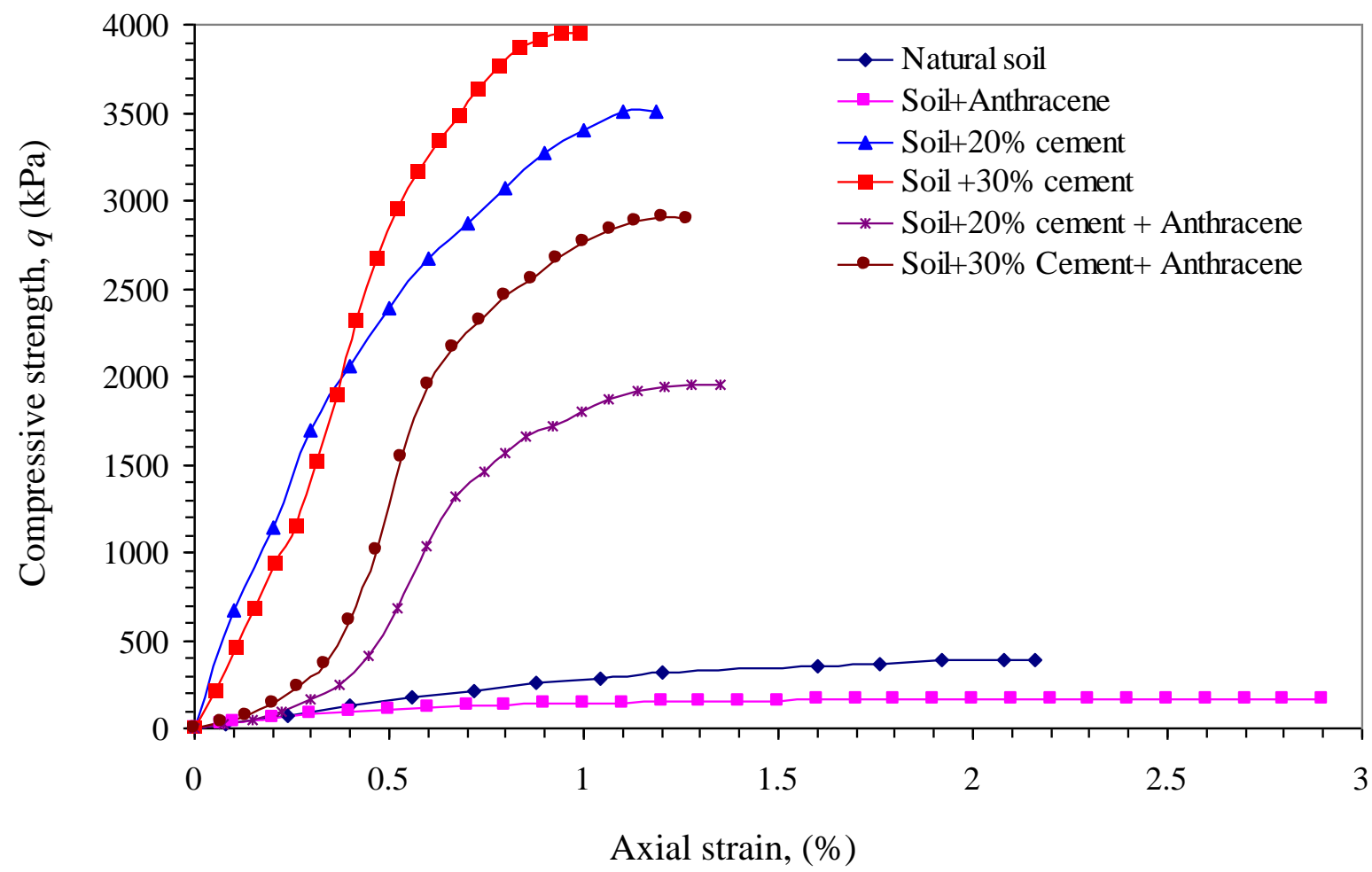

Fig.2 Stress-strain curves for natural soil, contaminated soil, uncontaminated and contaminated soil-cement with $20 \%$ and $30 \%$ cement at 7 days curing times 


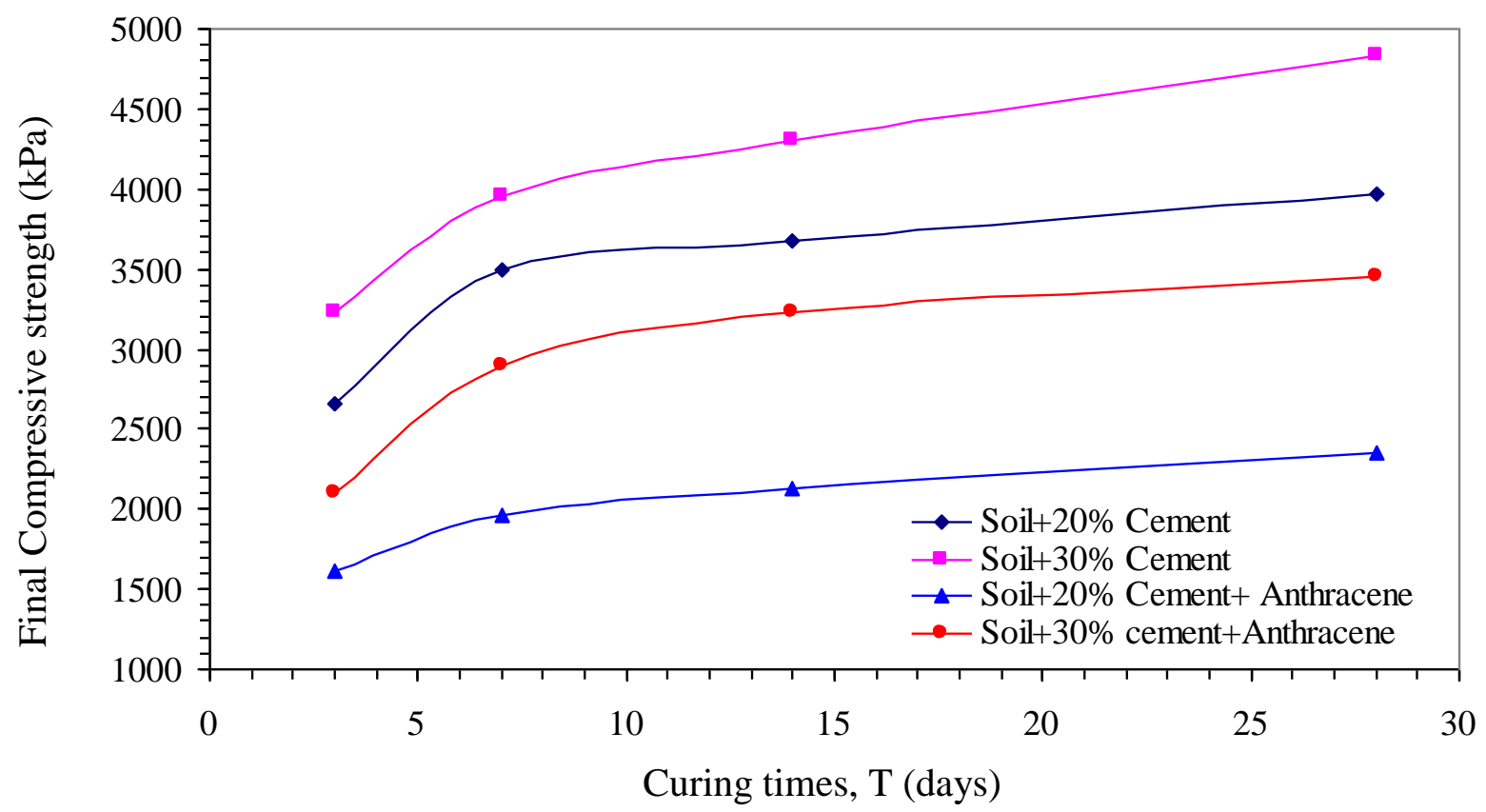

Fig.3 Final compressive strength with different curing time for contaminated and uncontaminated soil-cement at $20 \%$ and $30 \%$ cement 


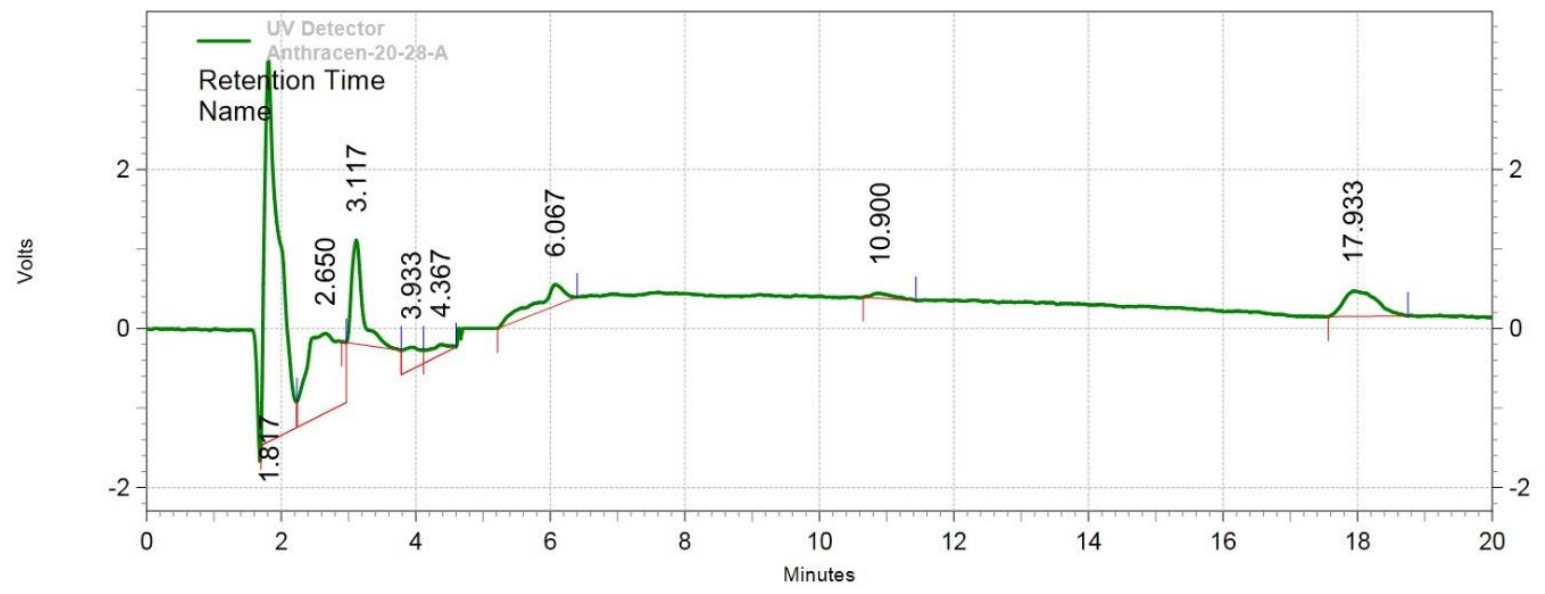

(a)

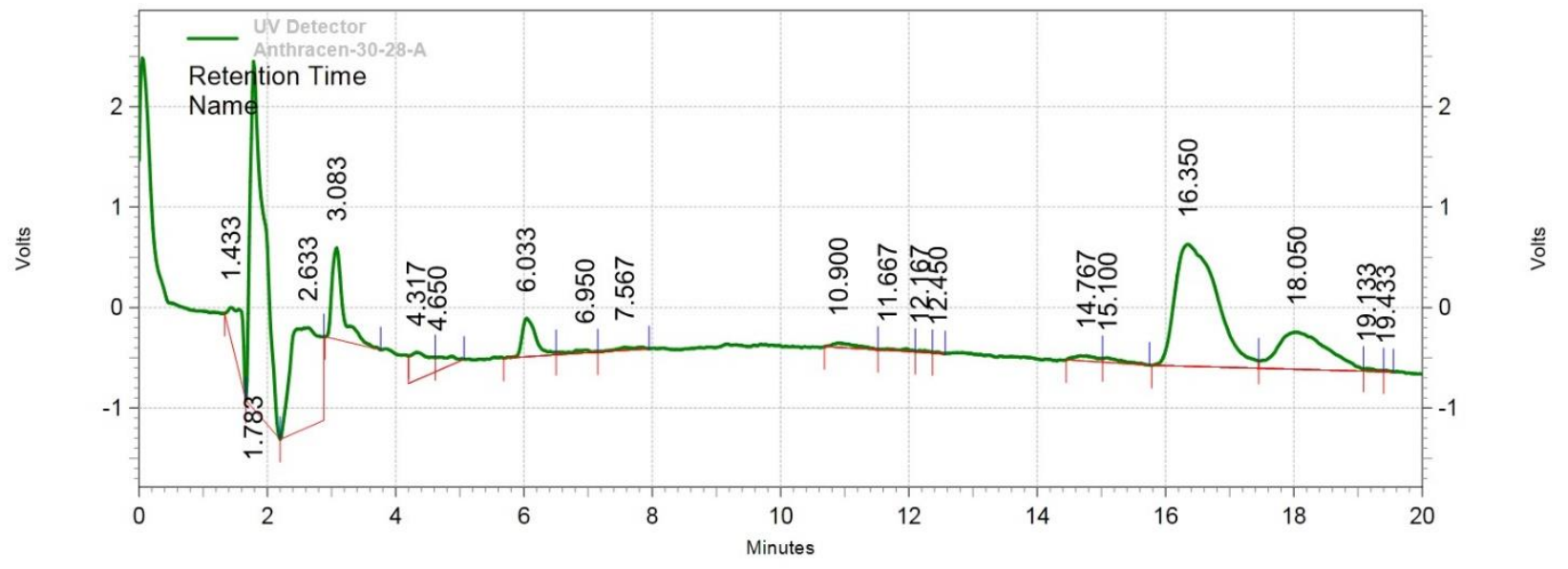

(b)

Fig.4 HPLC curves for injection of concentrated liquid from soil cement with (a)-20\% cement (b)- $30 \%$ cement at 28 days curing times 


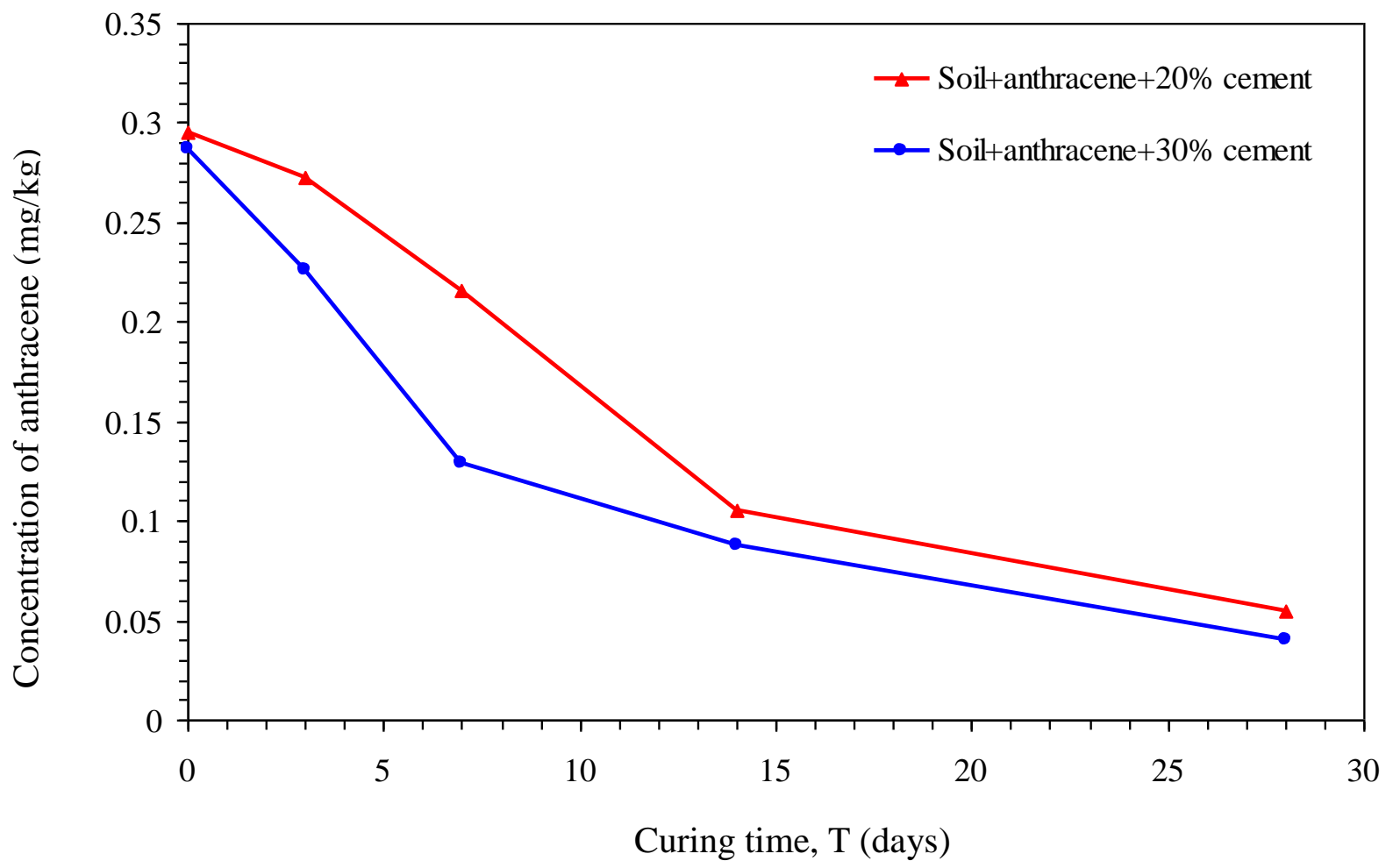

Fig.5 Concentration of anthracene after leaching for samples of contaminated soil mixed with $20 \%$ and $30 \%$ cement at different curing times 


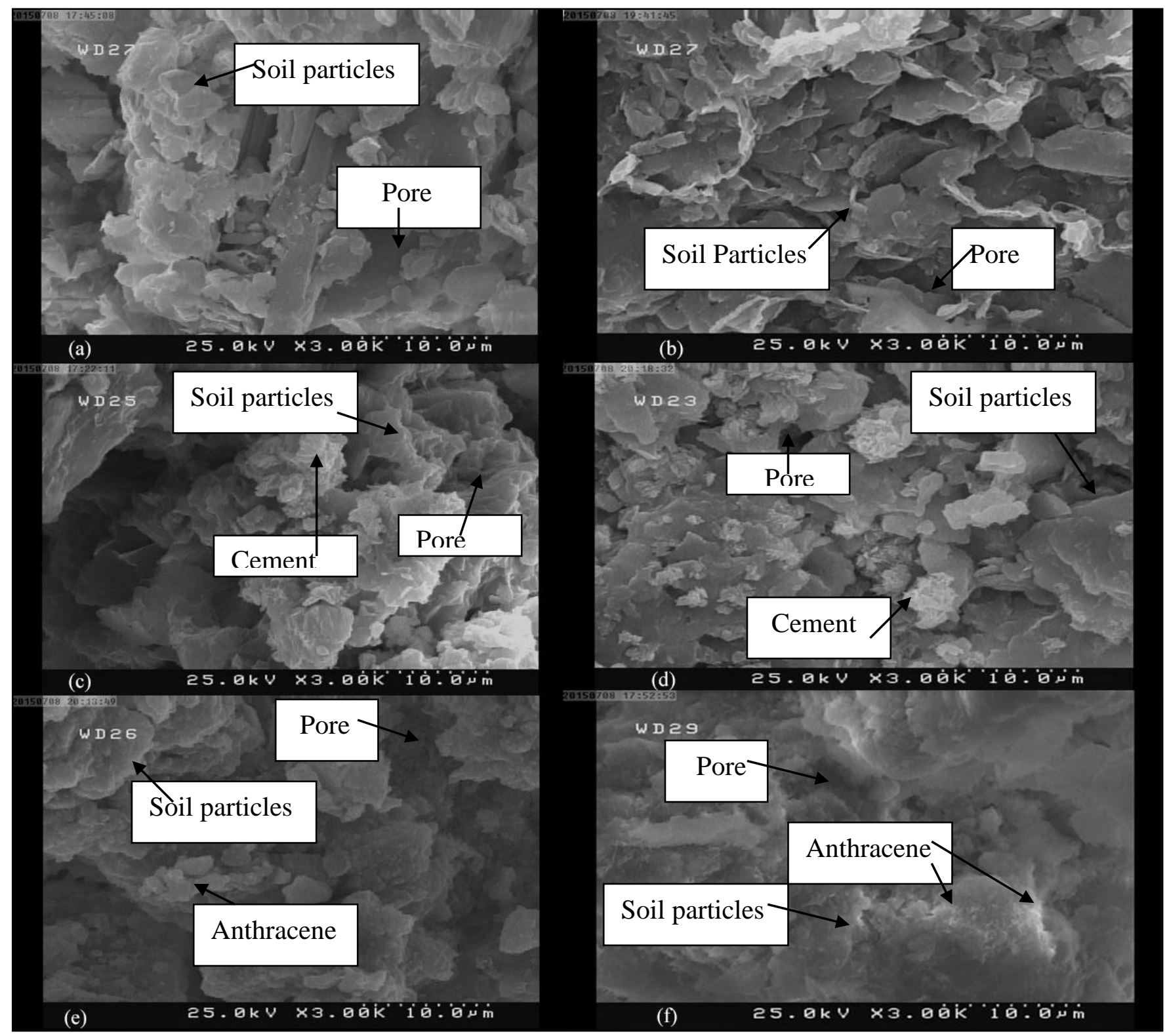

Fig.6 SEM images of (a) Natural soil, (b) Soil + anthracene, (c) Soil+20\% cement, (d) Soil $+30 \%$ cement, (e) Soil+anthracene+20\% cement, (f) Soil+anthracene $+30 \%$ cement 